


About IJMA
International Journal of Medical Arts is the Official Scientific Journal
of the Damietta Faculty of Medicine, Al-Azhar University, Egypt
It is an International, Open Access, Double-blind, Peer-reviewed,
monthly-published (starting January 2022) Journal
The First Issue was published in July 2019
Published under the following license: Creative Commons
Attribution-ShareAlike 4.0 International Public License (CC BY-SA
4.0).
The Egyptian Knowledge Bank hosts the web site and supports
IJMA follows the regulations of the International Committee of
Medical Journal Editors
IJMA is a member of the International Society of Managing and
Technical Editors
IJMA is indexed in the "Directory of Open Access Journals"
[Indexed on 15 January 2021], Index Copernicus and J-Gate [29-6-
IJM21].
IJMA Listed in
"Publons", "Academic resource index [ResearchBib]", "Electronics journal
Jibrary", "Eurasian Scientific Journal Index", World Catalogue of Scientific
WorldCat and "Citefactor"




Available online at Journal Website
https://ijma.journals.ekb.eg/
Main Subject [Surgery]

Original Article

\title{
Scrotal Orchiopexy and Classic Inguinal Orchiopexy for Unilateral Palpable Undescended Testes: A Randomized Case-Control Study
}

\author{
Ayub Ali ${ }^{[1]}$, Md Samiul Hasan $*^{[1]}$ \\ ${ }^{1}$ Department of Pediatric Surgery, Dhaka Shishu [Children] Hospital, Dhaka, Bangladesh
}

\begin{tabular}{|l||l||}
\hline Article information \\
Submitted: \\
Accepted: & $14-09-2021$ \\
$16-01-2022$ \\
DOI: $10.21608 /$ IJMA.2022.96068.1365 \\
\hline *Corresponding author \\
Email: samiulo45@gmail.com \\
\hline \hline Citation: Ali A, Hasan MS. Scrotal \\
Orchiopexy and Classic Inguinal \\
Orchiopexy for Unilateral Palpable \\
Undescended Testes: A Randomized Case- \\
Control Study. IJMA 2022 Jan; 4 [1]: 2068- \\
2072 [DOI: 10.21608/IJMA.2022.96068. \\
1365]. \\
\hline
\end{tabular}

ABSTRACT

Background: Undescended testis is a frequent anomaly in boys. Scrotal orchiopexy [SO] is gaining popularity over inguinal orchiopexy [IO] because of its simplicity.

The aim of the work: This study compared the outcome between SO and classical IO in unilateral palpable undescended testes.

Methods: Seventy boys with unilateral, palpable undescended testes were included in this study from January 2019 to December 2020. They were assigned to the SO and IO groups randomly using a lottery. The operative time and postoperative complications were compared between the two groups. The boys were followed up for six months to 2 years.

Results: The SO group had a significantly shorter operation time [35.26 \pm 5.153 minutes] than in the IO group [52.46 \pm 3.86 minutes] $[\mathrm{p}<0.001]$. One boy in the SO group and five boys in the IO group developed wound infection, which was not statistically significant. Scrotal hematoma, testicular atrophy, and testicular reascent were not seen in any group. No patient in the SO group required conversion to IO.

Conclusion: SO is a simple procedure that requires less time and minimum tissue handling. As a result, it causes less pain and better cosmetic outcome than the IO procedure.

Keywords: Undescended testis; Scrotal orchiopexy; Inguinal orchiopexy.

This is an open-access article registered under the Creative Commons, ShareAlike 4.0 International license [CC BY-SA 4.0] [https://creativecommons.org/licenses/by-sa/4.0/legalcode.

\section{INTRODUCTION}

The word cryptorchidism, derived from Greek 'Kryptos' [hidden], and 'orchis' [testis], means the absence of testis in the scrotum ${ }^{[1]}$. A cryptorchid testis may be an undescended testis [when it lies along the normal pathway of descent], an ectopic testis [when it deviates from the usual path], or an absent testis [never developed] ${ }^{[2,3]}$.

Undescended testis is a frequent anomaly of the male infant ${ }^{[1-3]}$, present in up to $8 \%$ of fullterm boys and up to $45 \%$ of premature boys at birth. The prevalence reduces to $1 \%$ of boys at the age of 1 year due to spontaneous descent ${ }^{[2}$, ${ }^{3]}$. Most of [About 80\%] of undescended testes are palpable and lie near external inguinal rings
[2,4-5]. However, the unilateral undescended testis is four times more frequent than the bilateral. Timely treatment is vital to avoid complications like infertility, testicular cancer, torsion, accompanying inguinal hernia, and psychological stigmata ${ }^{[6-8]}$.

As described by Schuller and Bevan, the classical orchiopexy for palpable undescended testis involves both inguinal and scrotal incisions to relocate the testis in the scrotal position $[2,4,8]$. It allows direct visualization of the spermatic cord, adequate mobilization, and higher resection of the hernial sac. Bianchi and Squire first argued that the testis lies close to the external inguinal ring in most cases, and adequate mobilization is possible through a high scrotal incision by dissecting the cremasteric 
fascia and processus vaginalis. Therefore, it is unnecessary to disrupt the inguinal canal through an inguinal incision, which also requires extra time and causes extra trauma to the patient. Since then, single SO has been gaining popularity. However, controversy remains. The main points of concern are gaining adequate cord length through a scrotal incision and ligating the processus high enough to avoid a hernia ${ }^{[9,10]}$.

\section{THE AIM OF THE WORK}

This study aims to compare the outcome of these two procedures [SO and IO] for unilateral palpable undescended testes prospectively.

\section{PATIENTS AND METHODS}

We have conducted a randomized casecontrol study from January 2019 to December 2020, where we included 70 patients with palpable undescended testes. After getting ethical clearance from the hospital's ethical review board, we included all children with unilateral undescended testis between 6 months to 12 years. Exclusion criteria were children with nonpalpable testis, previous inguinoscrotal surgery, or other comorbidities. We distributed them randomly in the case group [ 35 in the SO group] and the control group [35 in the IO group] by lottery. We have calculated the sample size using the formula for hypothesis testing of the difference between two means.

$$
\mathrm{n}=[[\mathrm{Z} \alpha+\mathrm{Z} \beta] 2 \times\{2[\mathrm{ó}] 2\}] /[\mu 1-\mu 2] 2
$$

Where, $\mathrm{n}=$ sample size required in each group, $\mu 1=62.3$ minutes [expected mean of operating time in classic inguinal incision approach] $\mu 2=40.5$ minutes [expected mean of operating time in single high trans-scrotal incision approach]13. $\mu 1-\mu 2=$ clinically significant difference $=21.5$ ó $=$ standard deviation of classic inguinal incision approach group $=35.6 . \mathrm{Z} \alpha=1.96[\mathrm{Z}$ value at $5 \%$ level of significance]. $Z \beta=0.85$ [at $80 \%$ power, when $\beta=0.2]$. Hence, the sample size was as follows: $\mathrm{n}=[[1.96+0.85] 2 \times\{2[35.6] 2\}] /[21.5] 2$ $=43.297 \approx 43$. So, according to this formula, each group required 43 participants. But considering the prevalence rate of undescended testis in our hospital, we have included 35 patients in each group.
The study's primary outcome was to validate the efficacy of SO in children. The secondary outcome variables were the differences in operation time, conversion to classic IO, and postoperative complications [ wound infection, Scrotal hematoma, Inguinal/scrotal congestion, testicular reascent, testicular atrophy] between SO and IO patients.

\section{Operative procedure}

\section{Scrotal orchidopexy [Figure 1]}

A high scrotal skin incision was made along the skin wrinkle. The subdarto pouch was made large enough for easy placement and fixation of the affected testis [Figure 1]. The dissection was continued toward the external inguinal ring. The wound was pulled upward to aid visualization and uncomplicated dissection. The dissection was continued upward and towards the inguinal canal to get an adequate length of the spermatic cord for a tension-free mobilization of the testis. The gubernacular attachments were resected to get more length. The cremasteric fibers and the patent processus vaginalis were separated from the cord structures and resected with care. The proximal end of the processus vaginalis was mobilized under traction into the canal. It was ligated with an absorbable suture, as in traditional inguinal incision orchiopexy. The testis was then pulled into the subdarto pouch and fixed in the upper pole, lower pole, and laterally. The scrotal wound was closed with interrupted absorbable sutures. A wall clock recorded the operation time.

\section{Classic inguinal orchidopexy (Figure 2)}

An incision was made along the inferior inguinal crease line over the external ring. The inguinal canal was opened, avoiding the injury to the ilioinguinal nerve. The Cremaster muscle and its fascia were split. The testis and spermatic cord were identified are freed from the surrounding structures.

The processus vaginalis [hernial sac] was dissected after being twisted, transfixed, and ligated. A tunnel was created from the inguinal canal into the scrotum. Another incision was made in the upper border of the scrotum, and a subdarto pouch was then created. The testis is then pulled down into the subdarto pouch and fixed. The inguinal and scrotal wounds were then closed in layers. 
All cases were followed up to 6 months postoperatively. Demographic and clinical data between the two groups were compared.

Informed consent: The study details were discussed with each patient's legal guardian, and written consent was taken.

Ethical clearance: Ethical clearance for this study was obtained from the ethical review board of Bangladesh Institute of Child Health and Dhaka Shishu Hospital.

Statistical analysis: The statistical analysis was conducted using SPSS [statistical package for social science] version 20 statistical software. Continuous data were assessed using a Student t-test, and associations of categorical data were assessed using the chi-square test. For both tests, $\mathrm{p}<0.05$ was considered significant.

\section{RESULTS}

Table 1 showed the differences in baseline characteristics between the groups, which were statistically non-significant. The mean operation time was $35.26 \pm 5.153$ and $52.46 \pm 3.86$ minutes in the $\mathrm{SO}$ and $\mathrm{IO}$ groups, respectively. $\mathrm{P}=$ 0.0001 [student t-test].

No patient in the SO group required conversion to IO. Postoperative complications were not significantly different in the two groups [Table 2].

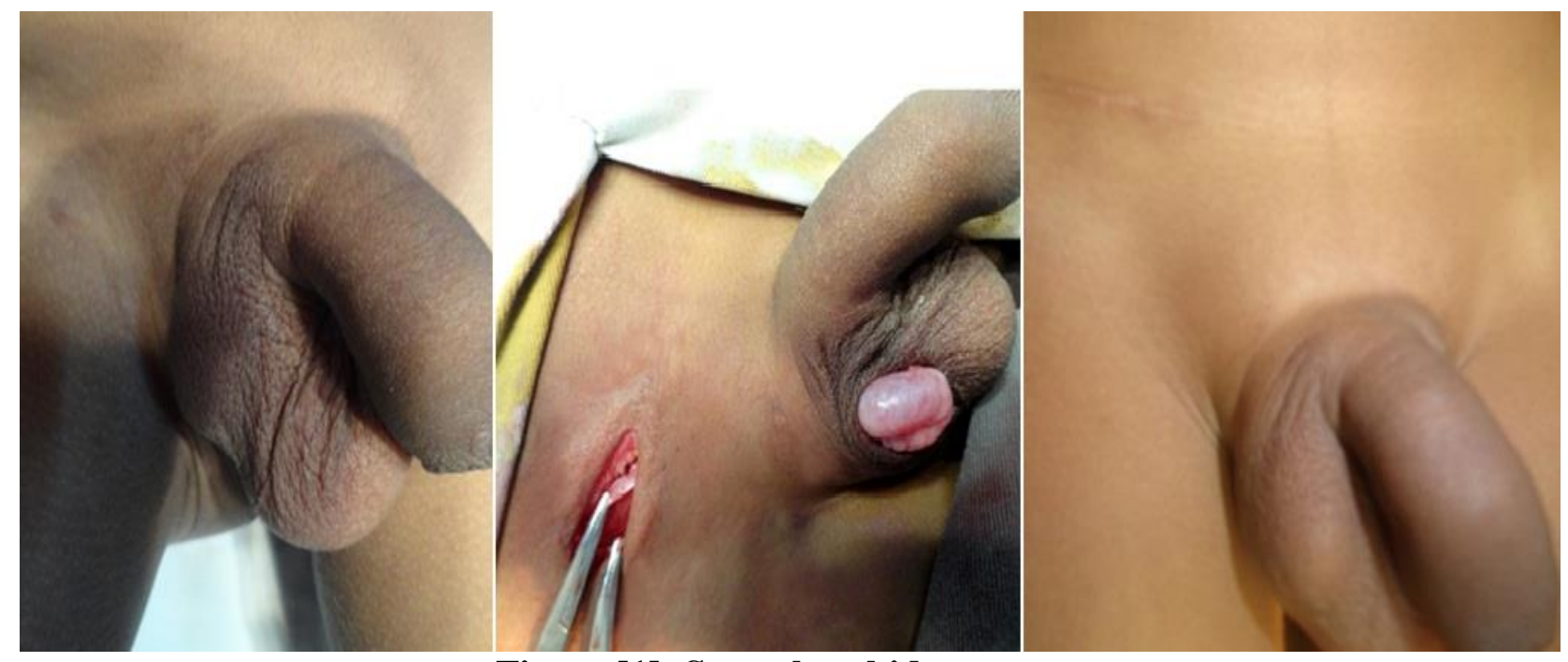

Figure [1]: Scrotal orchidopexy

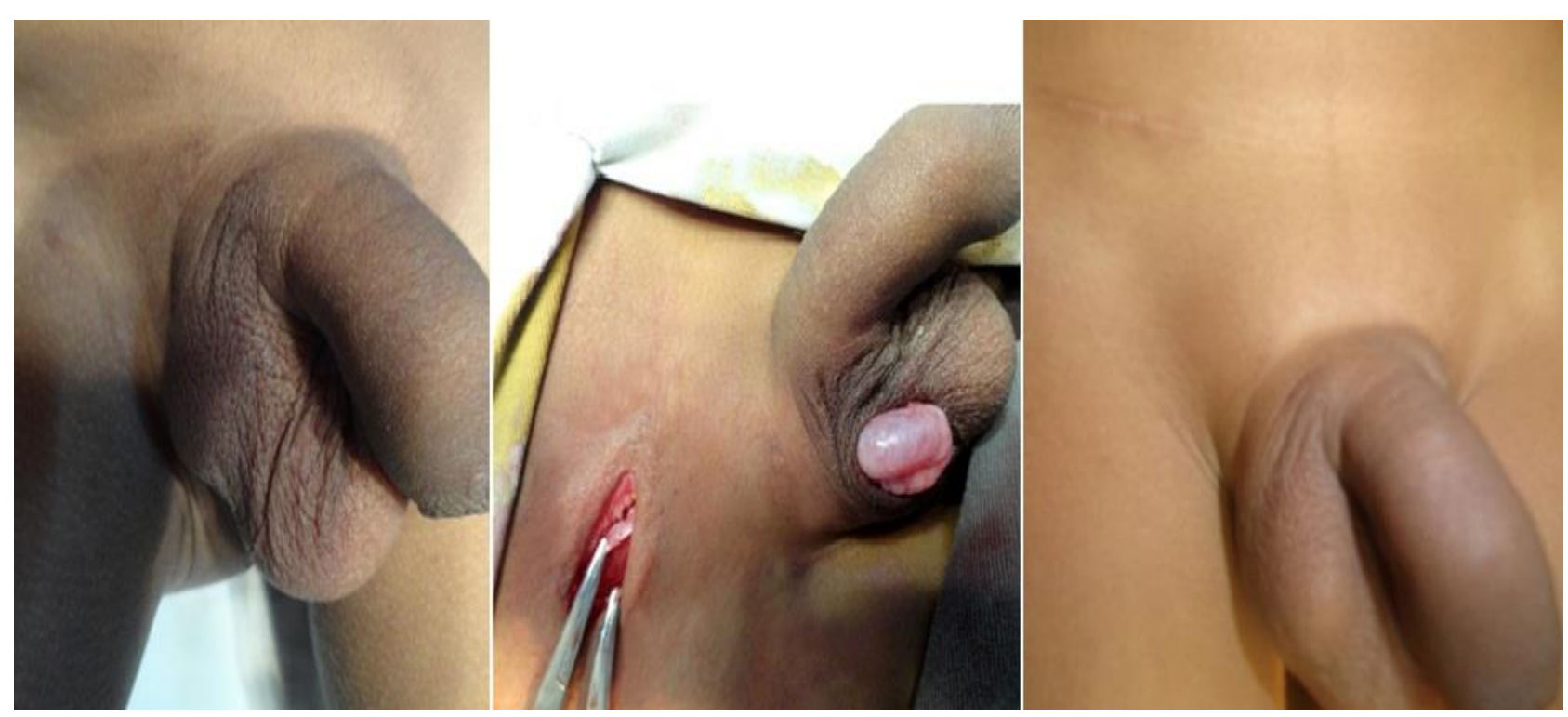

Figure [2]: Classic inguinal orchidopexy 
Table [1]: Baseline characteristics of the patients in SO and IO group

\begin{tabular}{|l|c|c|c|c|}
\multicolumn{2}{|c|}{ Baseline characteristics } & SO [n=35] & IO [n=35] & P-value \\
\hline Age in months & & $45.54 \pm 32.57$ & $44.49 \pm 33.97$ & 0.895 [t-test] \\
\hline $\begin{array}{l}\text { Affected } \\
\text { side }\end{array}$ & Right & $17[48.6 \%]$ & $22[62.8 \%]$ & 0.33 [Pearson's \\
\hline $\begin{array}{l}\text { Position } \\
\text { of the } \\
\text { testis }\end{array}$ & Left & $18[51.4 \%]$ & $13[37.2 \%]$ & Chi-square test] \\
\hline & $\begin{array}{c}\text { Superficial inguinal } \\
\text { Inguinal canal }\end{array}$ & $16[45.7 \%]$ & $23[65.7 \%]$ & 0.061 \\
& Neck of scrotum & $15[42.9 \%]$ & $12[34.3 \%]$ & [Pearson's Chi- \\
square test]
\end{tabular}

Table [2]: Postoperative complications between two groups

\begin{tabular}{|l|c|c|c|}
\hline Complications & SO $[\mathbf{n = 3 5}]$ & IO $[\mathbf{n = 3 5}]$ & P-value \\
\hline Wound infection & $1[2.9 \%]$ & $5[14.3 \%]$ & 0.198 \\
\hline Inguinal/scrotal congestion & $11[31.4 \%]$ & $13[37.1 \%]$ & 0.615 \\
\hline Hematoma & $0[0 \%]$ & $0[0 \%]$ & - \\
\hline Testicular re-ascent & $0[0 \%]$ & $0[0 \%]$ & - \\
\hline Testicular atrophy & $0[0 \%]$ & $0[0 \%]$ & - \\
\hline
\end{tabular}

\section{DISCUSSION}

The basic principles in the surgical management of orchidopexy were established in the last century, which involved concurrent inguinal and scrotal incisions [1]. However, testicular vessels and vas are long enough in most undescended testis cases. It allows adequate testis mobilization after resecting processus and cremasteric fibers ${ }^{[10]}$. So, in recent times, single scrotal incision orchidopexy is acceptable as it avoids inguinal explorations and potential complications $[2,4,5,8-10]$.

There is an overall consensus that early orchiopexy is beneficial for future fertility and may protect against the increased risk of testicular malignancy in cryptorchid patients ${ }^{[6}$, ${ }^{7]}$. In this study, the age of the participants was from 6 months to132 months [11 years]. Moreover, as the study was conducted in a hospital that allows patients up to 12 years, participants aged 11 years were included to follow-up for the next six months. Spontaneous descent of testis is possible up to the first three months, and beyond that, it is rare. So the recommended age of orchiopexy is six months $[3,6-7,11]$.

There was no conversion from the SO to the IO in this study. In a study by Ramzan et al., 10 out of 134 [7.4\%] patients required conversion into a two-incision inguinal approach due to tear of the hernial sac and inadequate mobilization ${ }^{[12]}$. Another study by Eltayeb showed that 3 out of 35 [8.5\%] cases of scrotal orchiopexy required conversion into a two-incision inguinal approach to gain more cord length [4] Conversion is mainly required in cases of the proximal lying testis though SO is successfully done even in nonpalpable testis ${ }^{[4,10]}$. In the present study, proximal lying testes were not included; probably that's why conversion was not required.

The main advantage of the SO technique, mentioned in most studies, was less operation time, which was also significantly less in this study. Though initial operations require a long time, it becomes shorter as soon as the surgeon gains confidence ${ }^{[4,12,13]}$.

The postoperative wound infection is one of the common complications after orchiopexy $[5,8,9]$. Though the infection rate was higher in the IO group, it was not statistically significant. This observation was similar to the study by Ramzan et al., where the wound infection was found in 2 [1.4\%] and 6 [4.4\%] respectively in two groups, which were not statistically significant $[p=0.151]^{[12]}$.

Scrotal hematoma, testicular reascent, and testicular atrophy were not observed in any group. However, these experiences are almost similar in most studies ${ }^{[5,8,9,12]}$, which depends on the surgeon's experience and delicacy of tissue handling.

We included a small number of patients in this study for time limitations. However, a larger sample size could better validate the results. The inclusion of children with proximal undescended testis could also influence the results. 
Conclusion: A SO is a safe and straightforward procedure for undescended tests in children. It avoids inguinal exploration, reduces tissue trauma, and gives an excellent cosmetic outcome. It requires less operation time, so it reduces theater time and cost.

Conflict of interest: No.

Financial disclosure: This study got no financial support.

\section{REFERENCES}

1. Park K, Choi H. An evolution of orchiopexy: historical aspect. Korean J Urol. 2010 Mar;51[3]:155-60.

DOI: 10.4111/kju.2010.51.3. 155.

2. Nazem M, Hosseinpour M, Alghazali A. Transscrotal Incision Approach versus Traditional Trans-scrotal Incision Orchiopexy in Children with Cryptorchidism: A Randomized Trial Study. Adv Biomed Res. 2019;8:34. DOI: 10.4103/abr.abr_26_19.

3. Rodprasert W, Virtanen HE, Mäkelä JA, Toppari J. Hypogonadism and Cryptorchidism. Front Endocrinol [Lausanne]. 2020 Jan 15;10:906. DOI: $10.3389 /$ fendo.2019.00906.

4. Eltayeb AA. Single high scrotal incision orchidopexy for unilateral palpable testis: a randomised controlled study. Afr J Paediatr Surg. 2014 Apr-Jun;11[2]:143-6. DOI: 10.4103/ 0189-6725.132808.

5. Chen L, Huang WH, Wang YJ, Zhang QL, Zhou CM, Cui X, Zhang JQ. Testicular descent and fixation through a scrotal stria incision for the treatment of palpable cryptorchidism in children aged <3 years: 10-year experience with 1034 cases. Asian J Androl. 2020;22[6]:649-652.

DOI: 10.4103/aja.aja_24_20.

6. Jay MA, Arat A, Wijlaars L, Ajetunmobi O, Fitzpatrick T, Lu H, et al. Timing of paediatric orchidopexy in universal healthcare systems: international administrative data cohort study. BJS Open. 2020 Jul 24;4[6]:1117-24. DOI: 10.1002/bjs5.50329.
7. Shin J, Jeon GW. Comparison of diagnostic and treatment guidelines for undescended testis. Clin Exp Pediatr. 2020 Nov;63[11]:415-421. DOI: $10.3345 /$ cep.2019.01438.

8. Nazem M, Hosseinpour M, Alghazali A. Transscrotal Incision Approach versus Traditional Trans-scrotal Incision Orchiopexy in Children with Cryptorchidism: A Randomized Trial Study. Adv Biomed Res. 2019 May 27;8:34. DOI: 10.4103/abr.abr_26_19.

9. Feng S, Yang H, Li X, Yang J, Zhang J, Wang A, Lai XH, Qiu Y. Single scrotal incision orchiopexy versus the inguinal approach in children with palpable undescended testis: a systematic review and meta-analysis. Pediatr Surg Int. 2016 Oct;32[10]:989-95. DOI: 10.1007/s00383-016-3956-4.

10. Gordon M, Cervellione RM, Morabito A, Bianchi A. 20 years of transcrotal orchidopexy for undescended testis: results and outcomes. J Pediatr Urol. 2010 Oct;6[5]:506-12. DOI: 10.1016/j.jpurol.2009.10.016.

11. Hutson JM, Hasthorpe S. Testicular descent and cryptorchidism: the state of the art in 2004. J Pediatr Surg. 2005 Feb;40[2]:297-302. DOI: 10.1016/j.jpedsurg.2004.10.033.

12. Ramzan M, Sheikh AH, Qureshi MA, Zubair M, Majid F. Single incision transscrotal versus standard inguino-scrotal orchidopexy in children with palpable undescended testis: our experience from April 2007 to April 2010. Pakistan J Med Sci. 2012; 28 [5]: 827-829.

13. Na SW, Kim SO, Hwang EC, Oh KJ, Jeong SI, Kang TW, Kwon DD, Park K, Ryu SB. Single scrotal incision orchiopexy for children with palpable low-lying undescended testis: early outcome of a prospective randomized controlled study. Korean J Urol. 2011 Sep;52[9]:637-41. DOI: 10.4111/kju.2011.52.9.637. 


\section{$1=\sqrt{202(2)}$}

international Journal https://ijma.journals.ekb.eg/ Print ISSN: 2636-4174 Online ISSN: 2682-3780

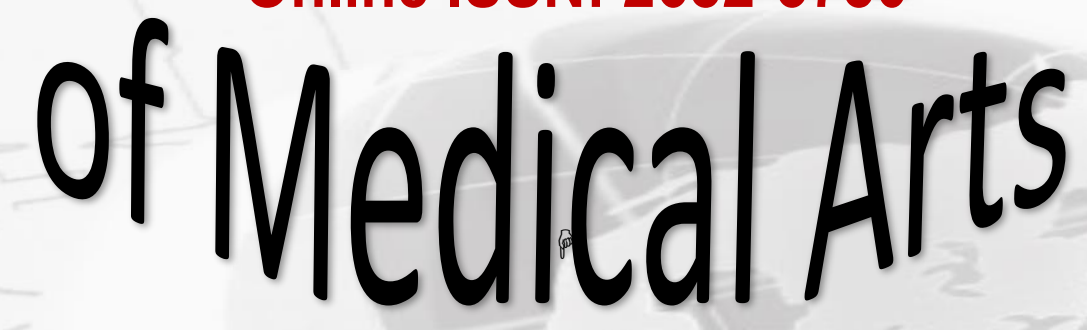

